\title{
Eyelid carcinomas: Tumor aggressiveness tendencies for smokers compared to non-smokers
}

\author{
RAZVAN MERCUT ${ }^{1 *}$, IRINA MARIA MERCUT ${ }^{2 *}$, ADINA DORINA GLODEANU $^{3}$, MIHAELA IONESCU $^{4 *}$, \\ ADINA TURCU ${ }^{4}$, ALIN STEFANESCU-DIMA ${ }^{2}$ and MARIUS EUGEN CIUREA ${ }^{1}$ \\ Departments of ${ }^{1}$ Plastic Surgery and Reconstructive Microsurgery, ${ }^{2}$ Ophthalmology and ${ }^{3}$ Internal Medicine, \\ ${ }^{4}$ Medical Informatics and Biostatistics, University of Medicine and Pharmacy of Craiova, 200349 Craiova, Romania
}

Received August 30, 2021; Accepted September 29, 2021

DOI: $10.3892 /$ etm.2022.11159

\begin{abstract}
During the past few years, several studies have demonstrated that head and neck carcinomas present more aggressive forms for smokers, relative to non-smokers. Our aim was to investigate the tumor aggressiveness for patients with eyelid carcinomas, in relation to tobacco consumption, as well as other demographic and clinical data. For 98 patients with eyelid carcinomas, we studied the relationship between the duration of their symptoms and their tumor stage at first diagnosis, trying to determine potential correlations with smoking status and several other clinical parameters. Our data revealed that, for the same duration of symptoms, tobacco consumers tended to have higher tumor stages, which did not correlate with other variables. For early diagnosed tumors, within the first year of symptoms, smokers presented 6.044 times higher odds to exhibit more advanced tumor stages, compared to non-smokers, and this value decreased to 4.501, up to 5 years of the presence of symptoms $(\mathrm{P}<0.05)$. We also noted that, for smokers, an increased age was associated with increased tumor stages, which was opposed to non-smokers, regardless of their symptom duration [average odds ratio (OR) 1.122, $\mathrm{P}<0.05$ ]. Tumor aggressiveness was therefore associated with tobacco consumption, leading to an increased risk of developing more aggressive forms of eyelid carcinomas for smokers, compared to non-smokers.
\end{abstract}

Correspondence to: Dr Adina Dorina Glodeanu, Department of Internal Medicine, University of Medicine and Pharmacy of Craiova, 2-4 Petru Rareş Street, 200349 Craiova, Romania

E-mail: adina.glodeanu@umfcv.ro

Dr Mihaela Ionescu, Department of Medical Informatics and Biostatistics, University of Medicine and Pharmacy of Craiova, 2-4 Petru Rareş Street, 200349 Craiova, Romania

E-mail:mihaela.ionescu@umfcv.ro

*Contributed equally

Key words: eyelid carcinoma, smoking, carcinogenesis, tumor aggressiveness, tobacco consumption

\section{Introduction}

Eyelid cancer represents a specific type of tumor that involves the skin of the eyelid or glands present at that level. The eyelid skin is considered the thinnest skin of the human body and may be easily impaired.

Skin cancer has the highest prevalence among cancers worldwide (1); head and neck cancers represent the sixth most common cancer and is defined by tumors growing in the nose or sinuses, mouth, throat, or larynx, or around the eyes, in the outer layer of the mucous membranes or the skin (2). Tumors located at the eyelid level account for 5 to $10 \%$ of all possible skin cancers, reflecting a rather common site (3).

There are four types of eyelid carcinomas: basal cell carcinoma (BCC), squamous cell carcinoma (SCC), sebaceous cell carcinoma, all three considered as non-melanoma skin cancer (NMSC), and melanoma. Almost $90 \%$ of all eyelid tumors are BCC, which is considered a type of carcinoma with a slow progression rate which rarely spreads in the surrounding areas. The other types are considered more aggressive, as they form, grow, or spread to other sites of the body more quickly.

The main carcinogenic factors for eyelid cancer are represented by UV exposure mostly during childhood and adolescence, fair skin, increased age, immunosuppression, and smoking $(3,4)$. Overall, tobacco is considered the main carcinogenic factor for $16 \%$ of all cancers in developed countries; in less developed regions, it accounts for around $10 \%$. There is a significant difference between sexes: for men, smoking is considered responsible for around $25 \%$ of all possible cancers, while for women, it only accounts for $4 \%(5,6)$.

Recent studies performed during the past 5-6 years have demonstrated that smoking may amplify the aggressiveness of tumors, especially head and neck carcinomas, favoring a more rapid progression to higher stages. Thus, tobacco is considered not only a carcinogenic factor, but it is also associated with an increased risk of developing aggressive forms of carcinomas. In fact, it was demonstrated that cigarette smoke can alter cell structures in indirect and direct ways (at the protein and DNA level) $(7,8)$ promoting tumoral cell proliferation.

The aim of the present study was to determine whether smokers present more aggressive forms of eyelid carcinomas, based on their current stage of tumors identified at first diagnosis, and the duration of their symptoms. 


\section{Patients and methods}

We conducted a research study between 2016 and 2019, on a group of 98 patients admitted to the Ophthalmology Clinic from the Emergency County Hospital Craiova, Romania.

The inclusion criterion was a diagnosis of eyelid neoplasm, no matter its form. All patients provided their informed consent regarding treatment and personal data analysis.

For each patient, we acquired the following data: sex, age at diagnosis, area of residency, tumor cell type, tumor stage and extension, status of relapse, treatment, smoking habit, data regarding the duration of symptoms at the moment of the initial consultation, as well as several clinical parameters (skin type, diabetes mellitus, arterial hypertension, cutaneous infections, actinic keratosis).

Given the available data, a patient was considered as a smoker if he/she was an active smoker, or he/she was a former smokers for a significant period of time (at least 1 year); otherwise, the patient was considered a non-smoker. Based on this status, we divided our study lot into two groups.

We determined the histopathological type of tumor as recommended by the World Health Organization (WHO) Classification of skin tumors (9). Tumor stage was assessed based on the TNM system (tumor, node, and metastasis) according to AJCC Cancer Staging 8th edition, which is a general classification of tumors according to their size and extent, relative to the original location (10). Following these criteria, tumors were divided in four ordered stages, named from T1 to T4.

Aggressiveness is a cancer characteristic, and it expresses the rapidity to which the tumor evolves from lower stages to higher stages. We assessed the aggressiveness level based on the tumor stage and the duration of symptoms at diagnosis.

Statistical analysis. We used Statistical Package for Social Sciences (SPSS), version 20 (IBM Corp.) to regroup patient data, to convert inputs into categorical parameters, and to perform a statistical analysis upon the acquired values. Chi-square and Fisher's exact tests were used to evaluate the studied group distributions and to compare different results. For each predefined interval of symptom duration, we used ordinal or binominal logistic regression to analyze the relation between tumor aggressiveness and smoking status, adjusting the result with sex and the age at first diagnosis.

We also determined the relative risk (RR) and 95\% confidence intervals (95\% CI) for smokers compared with non-smokers, in relation with several tumor-related parameters (P-value $<0.05$ was considered statistically significant). For risk calculation, tumor stage was dichotomized in mild (T1-T2) and severe (T3-T4) and non-smokers represented the reference group.

\section{Results}

The study lot had an almost equal distribution of sexes, with 51 males $(52.04 \%)$ and 47 females $(47.96 \%)$. More than half of the male patients were active smokers (28 patients, representing $54.90 \%$ of males), while only 17 females (representing $36.17 \%$ of females) smoked constantly (Table I).
Patients included in our study lot had age at diagnosis of a range between 39 and 91 years, mean value and standard deviation $67.4 \pm 12.53$, thus covering a significant age interval. To ease the subsequent analysis, the lot was divided into age decades, starting from 30-39 years. We obtained thus 6 decades, up to 90-99 years of age. To be consistent with the patients' real age, we named the decades from 3 to 9 , instead of 1 to 6 . Our study lot was composed mainly of patients with middle to high ages. Decades 5 and 6 each had almost a quarter of the entire group, decade 7 covered approximately $20 \%$, while decades $3,4,8$ and 9 represented the rest.

Table II contains the distribution of active smokers among the study lot, divided by age decade. Thus, decade 8 was the most affected, with $62.5 \%$ active smokers and $37.5 \%$ non-smokers. Decades 4 and 7 were equally divided (50\%), while the other decades were dominated by non-smokers. Greater differences in terms of smoking habit distribution were present for decades 5 and 8 .

Concerning the area of residence, most patients were from a rural environment (64 patients, representing 65.31\%), 28 females and 36 males, and almost half of all rural residents $(48.44 \%$, mostly males) were smokers $(31.63 \%$ of the entire lot). The rest of the 34 patients had an urban residence (34.69\%), 19 females and 15 males, and only $41.18 \%$ of the urban residents were active smokers (14.29\% of the entire lot) (Table I).

Two types of neoplasms were identified within our study lot: $87.76 \%$ (86 patients, 43 males and 43 females) had basal cell carcinoma (BCC), while $12.24 \%$ (12 patients, 8 males and 4 females) had squamous cell carcinoma (SCC). Less than half of the patients with BCC were active smokers $(46.51 \%$, $40 / 86$ patients, $60 \%$ of them being males) ( $40.82 \%$ of the entire lot). Among the patients with SCC, $41.67 \%$ were smokers (5/12 patients, only 1 female) (only $5.10 \%$ of the total lot). All 4 tumor stages (from T1 to T4) were identified among the patients (Table I).

We did not identified correlations between smoking status and sex, area of residence, tumor stage or neoplasm type $(\mathrm{P}>0.05)$ (Table I).

All patients had unilateral tumors, extended on the orbit for 8 patients ( $8.16 \%$ from the entire study lot). All 8 patients with orbit extensions had T4 stage tumors $(87.5 \%$ of them are from rural areas), and half of them are smokers. From the entire study lot, only 3 patients had relapse (3.06\%) with stages T1 and $\mathrm{T} 2$, all middle-aged males. All 3 were from rural areas, and two of them $(66.67 \%)$ were active smokers.

Analysis of symptom duration. During the initial consultation, patients were requested to declare for how long they presented clinical manifestations of their eyelid neoplasm; thus, we obtained the duration of the symptoms. Patients were divided in 3 categories: symptoms present for less than 1 year, symptoms present for a period between 1 and 5 years, and symptoms present for a period between 5 and 10 years (Table I).

Fig. 1 summarizes the evolution of smoker and non-smoker distribution among the study lot, indicating the increased tendency of the smoker proportion by stage, for patients with symptoms present for less than 5 years.

From the entire study lot, 42 patients (representing $42.86 \%$ ) came to the doctor after a few months of symptoms (less than 
Table I. Distribution of patients according to the duration of symptoms, tumor stage and type, sex, and smoking habit.

\begin{tabular}{|c|c|c|c|c|}
\hline Parameter & Total n (\%) & Smoker n (\%) & Non-smoker n (\%) & P-value $(\mathrm{M}, \mathrm{F})$ \\
\hline \multicolumn{5}{|l|}{ Sex } \\
\hline Male (M) & $51(52.04)$ & $28(28.57)$ & $23(23.47)$ & \multirow[t]{2}{*}{0.06} \\
\hline Female (F) & 47 (47.96) & $17(17.35)$ & $30(30.61)$ & \\
\hline \multicolumn{4}{|l|}{ Residency } & \multirow[t]{3}{*}{$0.49(\mathrm{M}, 0.88 ; \mathrm{F}, 0.59)$} \\
\hline Urban & 34 (34.69) & $14(14.29)$ & $20(20.41)$ & \\
\hline Rural & $64(65.31)$ & $31(31.63)$ & 33 (33.67) & \\
\hline \multicolumn{5}{|l|}{ Tumor stage } \\
\hline $\mathrm{T} 1$ & 37 (37.76) & $17(17.35)$ & $20(20.41)$ & \multirow[t]{4}{*}{$0.99(\mathrm{M}, 0.77 ; \mathrm{F}, 0.85)$} \\
\hline $\mathrm{T} 2$ & $31(31.36)$ & $14(14.29)$ & $17(17.35)$ & \\
\hline $\mathrm{T} 3$ & $22(22.45)$ & $10(10.20)$ & $12(12.24)$ & \\
\hline $\mathrm{T} 4$ & $8(8.16)$ & $4(4.08)$ & $4(4.08)$ & \\
\hline \multicolumn{4}{|l|}{ Type } & \multirow[t]{3}{*}{$0.75(\mathrm{M}, 0.76 ; \mathrm{F}, 0.63)$} \\
\hline $\mathrm{BCC}$ & $86(87.76)$ & $40(40.82)$ & $46(46.94)$ & \\
\hline $\mathrm{SCC}$ & $12(12.24)$ & $5(5.10)$ & $7(7.14)$ & \\
\hline \multicolumn{5}{|c|}{ Duration of symptoms } \\
\hline$<1$ year & $42(42.86)$ & $22(22.45)$ & $20(20.41)$ & \multirow[t]{3}{*}{$0.11(\mathrm{M}, 0.77 ; \mathrm{F}, 0.03)$} \\
\hline $1-5$ years & 37 (37.76) & $12(12.24)$ & $25(25.51)$ & \\
\hline 5-10 years & 19 (19.39) & $11(11.22)$ & $8(8.16)$ & \\
\hline
\end{tabular}

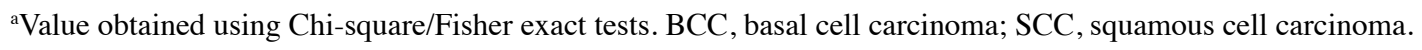

Table II. Distribution of patients according to age decade and smoking habit.

\begin{tabular}{lccccccc}
\hline Age decade & $30-39 \mathrm{n}(\%)$ & $40-49 \mathrm{n}(\%)$ & $50-59 \mathrm{n}(\%)$ & $60-69 \mathrm{n}(\%)$ & $70-79 \mathrm{n}(\%)$ & $80-89 \mathrm{n}(\%)$ & $90-99 \mathrm{n}(\%)$ \\
\hline Smoking habit & & & & & & \\
Smoker & $0(0)$ & $3(50)$ & $9(34.61)$ & $11(45.83)$ & $10(50)$ & $10(62.50)$ & $2(40)$ \\
Non-smoker & $1(100)$ & $3(50)$ & $17(65.39)$ & $13(54.17)$ & $10(50)$ & $6(37.50)$ & $3(60)$ \\
\hline
\end{tabular}

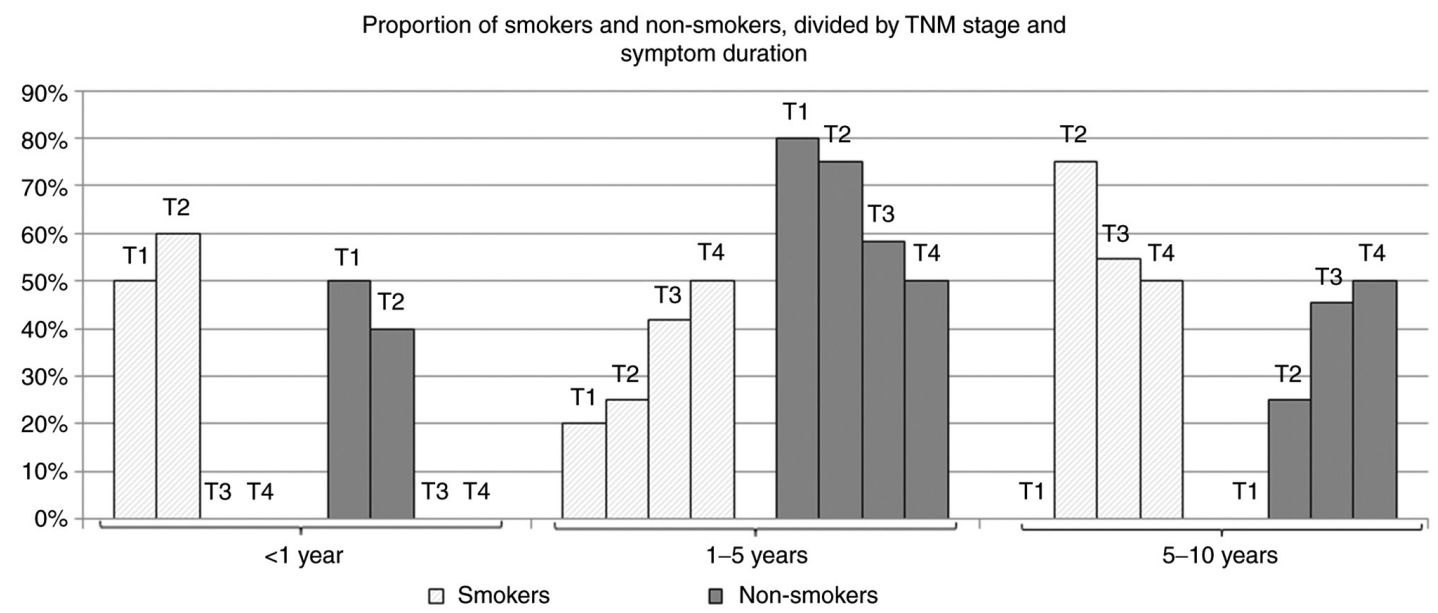

Figure 1. Distribution of smokers and non-smokers, according to TNM stage and symptom duration.

1 year): 17 females and 25 males (smokers represent $52.38 \%$ ) $(22.45 \%$ of the total lot). Mean age was $66.09 \pm 13.19$ years. Tumor distribution was the following: 32 patients $(76.19 \%)$
(32.65\% of the entire lot) had $\mathrm{T} 1$ tumors and $50 \%$ were smokers; 10 patients ( $10.20 \%$ of the entire lot) had T2 tumors, $60 \%$ of them were smokers. 

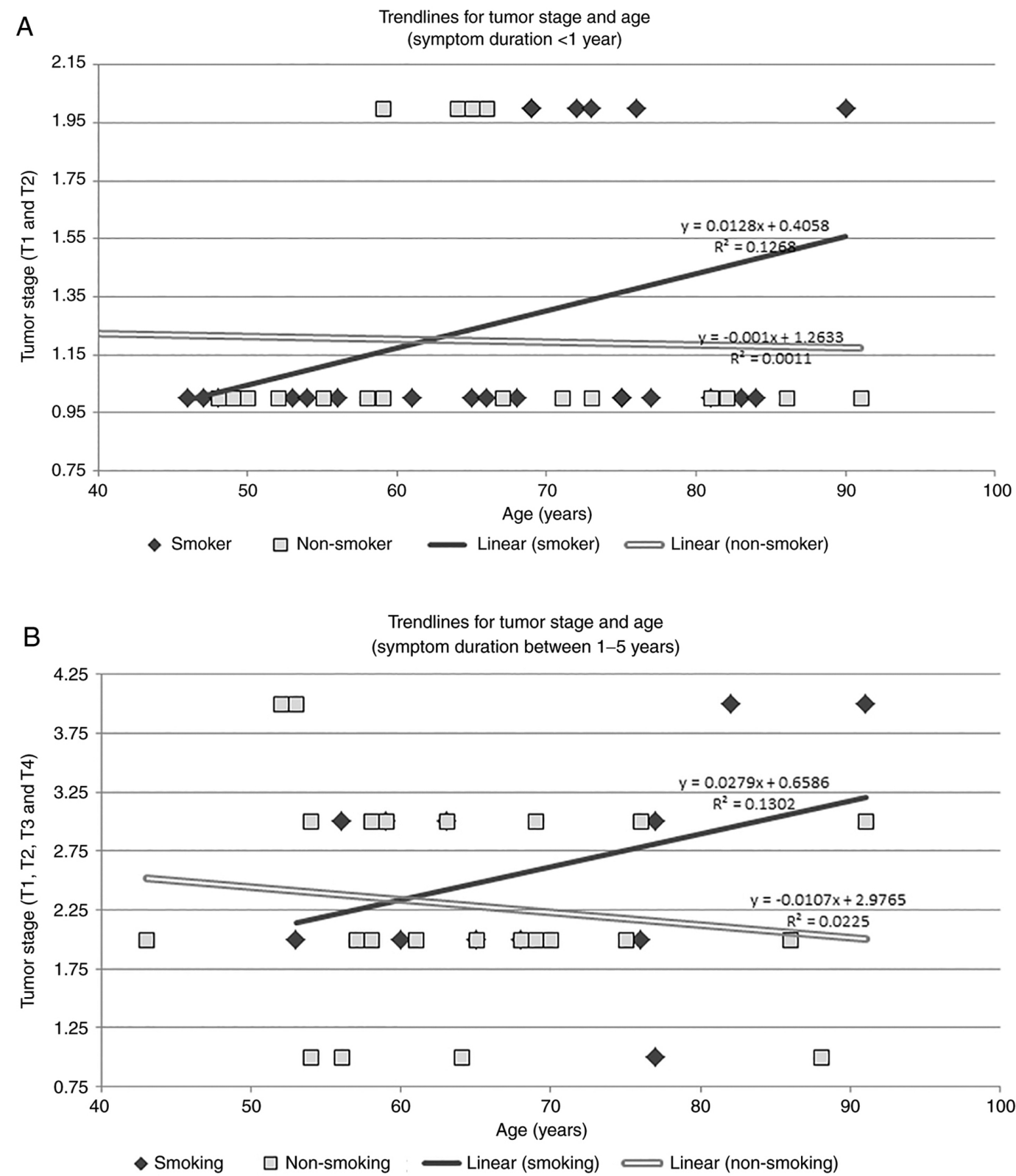

C

Trendlines for tumor stage and age (symptom duration between $5-10$ years)

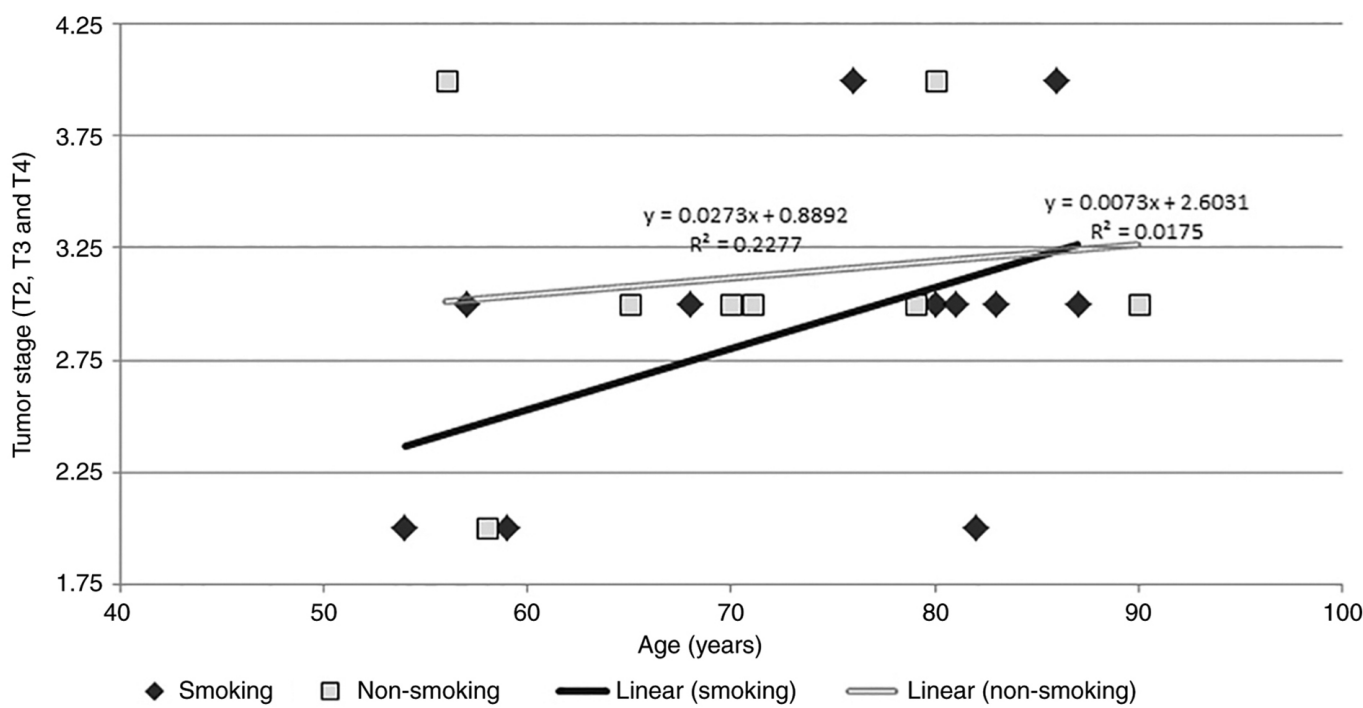

Figure 2. Trendlines for tumor stage and age, for symptoms (A) <1 year; (B) between 1 and 5 years; (C) between 5 and 10 years. 
The second duration category was 1-5 years and included 37 patients from the entire study lot $(37.76 \%, 19$ females and 18 males). Mean age was $66.13 \pm 11.71$ years. Only $32.43 \%$ of patients in this category were smokers $(12.24 \%$ of the total lot). Tumor stage distribution was the following: 5 patients had T1 tumors and 20\% were smokers; 16 patients had T2 tumors and $25 \%$ were smokers; 12 patients had T3 tumors and $41.67 \%$ were smokers; 4 patients had T4 tumors and $50 \%$ were smokers.

Within our study lot, we also had 19 patients $(19.39 \%$, 11 females and 8 males) who sought medical treatment after more than 5 years from their first clinical manifestations. Mean age was $72.73 \pm 11.71$ years. More than half of them (11/19 patients, $57.89 \%)$ were smokers (11.22\% of the total study lot).

Tumor stage distribution was the following: 4 patients had T2 tumors and $75 \%$ were smokers; 11 patients had T3 tumors and $54.5 \%$ were smokers; 4 patients had T4 tumors and $50 \%$ were smokers.

We identified a significant correlation between smoking and symptom duration only for females $(\mathrm{P}<0.05)$.

For the first two categories, the smoker proportion increased with the stage tumor; thus, the higher the stage, the higher percentage of smokers. Thus, for patients with symptoms present for less than 5 years, smokers had tumors of higher stages, more aggressive, compared to non-smokers. For category 5-10 years, the percentage of smokers decreased with the tumor stage. Smokers with symptoms present for more than 5 years apparently have less aggressive tumors, compared to non-smokers.

Age plays a role in tumor progression as well. For smoker patients whose symptoms were present for less than 1 year, tumor stage increased with age, compared with non-smokers, where the trend line indicated a decrease in stage with age (Fig. 2A). Only T1 and T2 stages are present in this category, thus we used a binomial logistic regression model to determine the potential effect of smoking status, sex, and age, upon the current tumor stage at first diagnosis. We initially used the Box-Tidwell procedure to test the linearity of age (the only continuous variable), and the results confirmed that it was linearly related to the logit of the tumor stage $(\mathrm{P}=0.972$, which was greater than the standard value 0.05 , and also value 0.0125 , computed using the Bonferroni correction). Our model was statistically significant, with $\chi^{2}(4)=27.402, \mathrm{P}<0.0005$. Only 2 of the 3 variables used as predictors were significant: age and smoking status. Smokers presented 6.044 times higher odds to have more advanced tumor stages, compared to non-smokers (95\% CI, 1.240-54.141), $\left.\chi^{2}(1)=4.768, \mathrm{P}=0.029\right)$. Similarly, older patients had 1.141 times higher odds, compared to younger patients $\left.(95 \% \mathrm{CI}, 1.203-14.171), \chi^{2}(1)=4.167, \mathrm{P}=0.041\right)$.

A similar evolution was identified for patients with symptoms present between 1 and 5 years, where tumors were more aggressive with age for smokers, compared to non-smokers (Fig. 2B). Given the fact that patients from this category exhibited all 4 types of tumors, we used ordinal logistic regression to identify the potential effect of smoking status, sex, and age, upon the current tumor stage at first diagnosis. We assessed the proportional odds through a full likelihood ratio test (our fitted model was compared to a model characterized by varying location parameters), obtaining $\chi^{2}(6)=7.221, \mathrm{P}=0.301$. The final model was able to assess the tumor stage, $\chi^{2}(4)=12.891$,
Table III. Risk estimation for smokers compared to non-smokers.

\begin{tabular}{lc} 
Parameter & Smokers RR $(95 \%$ CI $)$ \\
\hline Sex & \\
Female & $0.667(0.429-1.039)$ \\
Male & $1.434(0.978-2.102)$ \\
Residency & \\
Urban & $0.824(0.473-1.437)$ \\
Rural & $1.106(0.830-1.474)$ \\
Type & \\
SCC & $0.841(0.287-2.469)$ \\
BCC & $1.024(0.884-1.187)$
\end{tabular}

Tumor stage

T1-T2

$0.987(0.758-1.285)$

T3-T4

$1.031(0.567-1.873)$

Symptoms $<1$ year

T1

$0.909(0.649-1.273)$

$\mathrm{T} 2$

$1.364(0.449-4.141)$

Symptoms 1-5 years

T1-T2

$0.781(0.413-1.478)$

T3-T4

$1.389(0.643-3.000)$

Symptoms 5-10 years

T1-T2

$2.182(0.275-17.322)$

T3-T4

$0.831(0.532-1.299)$

RR, relative risk; CI, confidence interval; SCC, squamous cell carcinoma; BCC, basal cell carcinoma.

$\mathrm{P}=0.005$. The computed odds of smokers having advanced tumor stages were 4.501 times greater than for non-smokers (95\% CI, 1.076-18.820), $\chi^{2}(1)=4.246, P=0.039$. Sex had no statistically significant influence over more advanced tumor stages, $\chi^{2}(1)=1.410, P=0.235$. We identified an association between a higher age and an increase of odds for patients presenting higher tumor stages, with a computed odds ratio of $1.077\left(95 \%\right.$ CI, 1-1.119), $\chi^{2}(1)=3.697$, and a borderline value of $\mathrm{P}=0.05$.

For patients in the last category of symptom duration, there was an increased tendency to higher stages with age, for both smokers and non-smokers (Fig. 2C). With 3 tumor stages identified for this category, from $\mathrm{T} 2$ to $\mathrm{T} 4$, we ran a similar ordinal logistic regression model. Odds were proportional for our parameters: $\chi^{2}(3)=3.055, \mathrm{P}=0.383$. The final model was able to assess the tumor stage, $\chi^{2}(3)=8.915, \mathrm{P}=0.030$. Smoking status or sex had no significant effects over advanced tumor stages, with $\chi^{2}(1)=1.464, P=0.226$, respectively $\chi^{2}(1)=0.154$, $\mathrm{P}=0.695$. However, we also identified an association between a higher age and an increase of odds for patients presenting higher tumor stages, with an odds ratio of 1.150 (95\% CI, 1.028-1.287), $\chi^{2}(1)=5.942, \mathrm{P}=0.015$.

We also performed various analyses upon clinical and demographical data, by sex and age decades, but we did not find any specific tumor progression correlations $(\mathrm{P}>0.05)$. Table III contains the relative risk analysis for smokers with 
non-smokers as reference, determined for sex, residency, cell type, tumor stage and symptom duration.

\section{Discussion}

Tobacco smoking has been around for more than 2000 years ago, either part of religious ceremonies, or simply for entertainment in more recent times. Before 1800 , there were just a few attempts to link smoking with diseases. But this habit (later defined as a vice) started to be considered dangerous only around the 1920 's; studies continued in a more organized manner until 1950-1960, when a series of major results were clearly reported and confirmed that tobacco smoking led to lung cancer (11).

Almost half of the patients included in our study lot were smokers. The simple notion of a smoker is however complex since several types of smoking are defined: active (or first-hand) and passive (or second hand). A series of studies have demonstrated that passive smoking is frequent. Whether it is smoke from a burning cigarette, or the smoke exhaled by a smoker nearby, we may consider that most people are exposed to tobacco smoke. Data from the literature indicate that more than a quarter of non-smokers (27.5\%) are exposed to secondhand smoke; women being more exposed than men (12-14). Similar results were obtained by Oberg et al (15) in Easter Mediterranean and South-East Asia, with other authors also reporting that women are at least $50 \%$ more susceptible of passive smoking than men $(16,17)$.

Several years ago, a series of studies analyzed the remainder of particles from first-hand tobacco smoke. These particles get attached to dust and various surfaces and they remain there for a long period after the original smoke is no longer present. In this case, individuals present in this area are exposed to third hand smoke (also known as residual tobacco smoke) (18).

From our study lot, $45.92 \%$ were active smokers, thus exposed to first-hand tobacco smoke. People who smoke actively, or simply stay in an environment where there is cigarette smoke, are exposed to an ensemble of more than 7000 chemicals; among them, there are at least 250 toxins with carcinogenic potential. Some of them have an upregulatory effect on several oncogenes and transcriptional constituents that may favor carcinogenesis (19). Others are involved in carcinogenesis through various mechanisms that interact with cancer genes or may produce changes at the molecular level and alter the normal cell cycle, deregulate apoptosis or autophagy processes, or increase the ability to invade the surrounding areas (20-23). Studies have found that residues from smoke may combine with gases from the surrounding air, thus forming cancer-inducing components that remain on hands or on surfaces (24-26). These substances have the potential to damage human DNA or impact blood clotting (27-29).

Tumor aggressiveness. Recent studies have reported increased tumor progression rates for smokers, compared to non-smokers. This aggressiveness is due to catabolic transporters and oxidative stress, since tobacco smoke may favor tumor stroma shifting toward glycolysis (2). Stroma cells have a supporting role within the tumor itself and represent more than half of all tumoral cells. Fibroblasts are the most common stroma cells and promote tumor progression by generating metabolic products that act like a fuel for cancer cells. Domingo-Vidal et al reported that fibroblasts exposed to cigarette smoke favor increased glycolysis, thus generating more metabolites for tumor cells, which accelerated their proliferation (2). Moreover, tumor cells become more resistant to apoptosis and acquire increased mobility (30). Based on tumor cell types, smokers from our study had similar rates of prevalence for basal cell carcinoma (BCC) and squamous cell carcinoma (SCC); however Leonardi-Bee et al reported that tobacco consumption increases the risk of developing SCC with 52\% (1). Still, the number of our SCC patients was rather small, thus we will continue research in this direction. Other authors have reported that there also are other factors activated by nicotine that favor tumoral cell proliferation (31-34). Overall, our findings are similar, as active smokers present higher stage tumors, compared to non-smokers. Periodic screening and early risk assessment may shift this balance in the future years, as the use of artificial intelligence, especially machine learning, increases the efficiency of these processes and diminishes the burden of physicians in this direction (35-38).

According to our data, eyelid carcinoma and smoking status are correlated with females, and similar results have been reported by MercuŢ et al (39) and Wojno (40). In addition, smokers present a higher risk to develop severe forms of tumors in the first months/years of symptomatology. From all patients with symptoms present for less than a year, for all tumor stages in this category (only mild), the number of smokers was at least equal or higher compared to non-smokers. T1 was predominant in this group, since patients sought medical treatment from their very first symptoms. T2 group was dominated by smokers. A similar status was valid for patients with a symptom duration between 1 and 5 years. As the tumor stage increased, so was the number of smoker patients within that category. Therefore, comparing the distribution of smokers vs. non-smokers, tobacco consumers had, once again, more advanced tumor stages, supporting the fact that smoking accelerates tumor progression rates, which indicates more aggressive behaviors. The same analysis yielded different results for group with symptoms between 5 and 10 years. This category was the smallest, with only 19 patients, from whom 13 had a rural residency ( $61.54 \%$ of them were smokers). After at least 5 years, it was obvious that there were no patients with $\mathrm{T} 1$ tumors, but most smokers had T2 tumors, followed by T3 and T4 tumors. Compared to the other two groups, the number of smokers was decreased when the stage was increased. We can only say that, at this point, smokers are either no longer smoking (they quit smoking before the diagnosis), or this is possible evidence that smoking, in association with carcinomas, does not sustain a long-life expectancy.

Our study presents several limitations. The smoker status was assessed only based on active smoking or former smoking for a significant period of time, as we encountered difficulties in gathering data regarding the smoking period, expressed in number of years, estimated number of cigars/day, or type of cigarettes/pipe. Also, the duration of symptoms was the one reported by each patient before inclusion in our study, without having a consistent method of definition, and it is based on their personal perception of symptoms, which may be a subjective estimation as it lacks a common reference. 
In conclusion, tobacco smoke contains many components that are involved in carcinogenesis and tumor progression and aggressiveness. Smoking accelerates the progression rate, thus reaching a higher stage if the patient is an active smoker, compared to non-smokers for whom the tumor stage evolution is less rapid.

\section{Acknowledgements}

Not applicable.

\section{Funding}

This work was supported by a research grant entitled "Development of a prediction system regarding the evolution of non-melanoma skin cancer, for individualized treatment", financed by the University of Medicine and Pharmacy of Craiova, Romania, 2021 (Internal competition).

\section{Availability of data and materials}

The datasets used and/or analyzed during the current study are available from the corresponding author on reasonable request.

\section{Authors' contributions}

RM, IMM and MI conceptualized the study, prepared the initial draft, and share first authorship. ADG, AT and ASD performed the literature data collection. MEC provided critical revision in light of the collected data. All authors have read and approved the final version of the manuscript for publication.

\section{Ethics approval and consent to participate}

Informed consent was obtained from all patients. For our study, we obtained prior approval from the Ethics Committee of the University of Medicine and Pharmacy of Craiova, Romania.

\section{Patient consent for publication}

Not applicable.

\section{Competing interests}

The authors declare that they have no competing interests.

\section{References}

1. Leonardi-Bee J, Ellison T and Bath-Hextall F: Smoking and the risk of nonmelanoma skin cancer: Systematic review and meta-analysis. Arch Dermatol 148: 939-946, 2012.

2. Domingo-Vidal M, Whitaker-Menezes D, Martos-Rus C Tassone P, Snyder CM, Tuluc M, Philp N, Curry J and Martinez-Outschoorn U: Cigarette smoke induces metabolic reprogramming of the tumor stroma in head and neck squamous cell carcinoma. Mol Cancer Res 17: 1893-1909, 2019.

3. Silverman N and Shinder R: What's new in eyelid tumors. Asia Pac J Ophthalmol (Phila) 6: 143-152, 2017.

4. Balasubramanian A and Kannan N: Eyelid malignancies-always quite challenging. J Clin Diagn Res 11: XR01-XR04, 2017.

5. Sasco AJ, Secretan MB and Straif K: Tobacco smoking and cancer: A brief review of recent epidemiological evidence. Lung Cancer 45 (Suppl 2): S3-S9, 2004.
6. Khani Y, Pourgholam-Amiji N, Afshar M, Otroshi O, Sharifi-Esfahani O, Sadeghi-Gandomani H, Vejdani M and Salehiniya H: Tobacco smoking and cancer types: A review. Biomed Res Ther 5: 2142-2159, 2018.

7. Tonini G, D'Onofrio L, Dell'Aquila L and Pezzuto A: New molecular insights in tobacco-induced lung cancer. Future Oncol 9: 649-655, 2013

8. Pezzuto A, Citarella F, Croghan I and Tonini G: The effects of cigarette smoking extracts on cell cycle and tumor spread: novel evidence. Future Sci OA 5: FSO394, 2019.

9. Elder DE, Massi D, Scolyer RA and Willemze R (eds): World Health Organization (WHO) Classification of Skin Tumours. 4th edition. International Agency for Research on Cancer (IARC) Press, Lyon, pp7-14, 2018.

10. Amin MB, Edge S, Greene F, Byrd DR, Brookland RK, Washington MK, Gershenwald JE, Compton CC, Hess KR, Sullivan DC, et al (eds): AJCC cancer staging manual (8th edition). Springer International Publishing, American Joint Commission on Cancer, 2017.

11. Brandt AM: Cigarette Century: the Rise, Fall and Deadly Persistence of the Product that Defined America. Basic Books, New York, NY, 2007.

12. Salimzadeh H, Najafipour H, Mirzaiepour F, Navadeh S, Shadkam-Farrokhi M and Mirzazadeh A: Prevalence of active and passive smoking among adult population: Findings of a population-based survey in Kerman (KERCADRS), Iran. Addict Health 8: 16-24, 2016.

13. Parkin D, Boyd L and Walker L: 16. The fraction of cancer attributable to lifestyle and environmental factors in the UK in 2010. Br J Cancer 105 (Suppl 2): S77-S81, 2011.

14. Lim SS, Vos T, Flaxman AD, Danaei G, Shibuya K, Adair-Rohani H, Amann M, Anderson HR, Andrews KG, Aryee M, et al: A comparative risk assessment of burden of disease and injury attributable to 67 risk factors and risk factor clusters in 21 regions, 1990-2010: A systematic analysis for the global burden of disease study 2010. Lancet 380: 2224-2260, 2014.

15. Oberg M, Jaakkola MS, Woodward A, Peruga A and Prüss-Ustün A: Worldwide burden of disease from exposure to second-hand smoke: A retrospective analysis of data from 192 countries. Lance 377: 139-146, 2011.

16. Ferrante G, Simoni M, Cibella F, Ferrara F, Liotta G, Malizia V, Corsello G, Viegi F and La Grutta S: Third-hand smoke exposure and health hazards in children. Monaldi Arch Chest Dis 79: 38-43, 2013.

17. Martins-Green M, Adhami N, Frankos M, Valdez M, Goodwin B, Lyubovitsky J, Dhall S, Garcia M, Egiebor I, Martinez B, et al: Cigarette smoke toxins deposited on surfaces: Implications for human health. PLoS One 9: e86391, 2014.

18. Jacob P III, Benowitz NL, Destaillats H, Gundel L, Hang B, Martins-Green M, Matt GE, Quintana PJE, Samet JM, Schick SF, et al: Thirdhand smoke: New evidence, challenges, and future directions. Chem Res Toxicol 30: 270-294, 2017.

19. Hussain A, Dulay P, Rivera MN, Aramuni C and Saxena V: Neoplastic pathogenesis associated with cigarette carcinogens. Cureus 11: e3955, 2019

20. Kim CW, Lee HM, Lee K, Kim B, Lee MY and Choi KC: Effects of cigarette smoke extracts on cell cycle, cell migration and endocrine activity in human placental cells. Reprod Toxicol 73: 8-19, 2017.

21. Xu L, Mao XY, Fan CF and Zheng HC: MTA1 expression correlates significantly with cigarette smoke in non-small cell lung cancer. Virchows Arch 459: 415-422, 2011.

22. Zaharie M, Carstea D, Streba CT, Mitrut P, Glodeanu AD, Carstea AP, Zaharie SI, Dascalu IT, Tuculina MJ, Bunget A, et al: Renal dysfunction-a possible marker of severity of heart failure. Rev Chim 69: 1435-1440, 2018.

23. Tian D, Zhu M, Li J, Ma Y and Wu R: Cigarette smoke extract induces activation of beta-catenin/TCF signaling through inhibiting GSK3beta in human alveolar epithelial cell line. Toxicol Lett 187: 58-62, 2009.

24. Sleiman M, Gundel LA, Pankow JF, Jacob P III, Singer BC and Destaillats $\mathrm{H}$ : Formation of carcinogens indoors by surface-mediated reactions of nicotine with nitrous acid, leading to potential thirdhand smoke hazards. Proc Natl Acad Sci USA 107: 6576-6581, 2010.

25. Thomas JL, Hecht SS, Luo X, Ming X, Ahluwalia JS and Carmella SG: Thirdhand tobacco smoke: A tobacco-specific lung carcinogen on surfaces in smokers' homes. Nicotine Tob Res 16: 26-32, 2014. 
26. Hoh E, Hunt RN, Quintana PJ, Zakarian JM, Chatfield DA, Wittry BC, Rodriguez E and Matt GE: Environmental tobacco smoke as a source of polycyclic aromatic hydrocarbons in settled household dust. Environ Sci Technol 46: 4174-4183, 2012

27. Hang B, Sarker AH, Havel C, Saha S, Hazra TK, Schick S, Jacob P III, Rehan VK, Chenna A, Sharan D, et al: Thirdhand smoke causes DNA damage in human cells. Mutagenesis 28: 381-391, 2013.

28. Cârstea D, Streba LA, Glodeanu AD, Cârstea AP, Vancu M and Ninulescu AM: The accuracy of combined physical examination and ultrasonography for the detection of abdominal aorta aneurysm. Rom J Morphol Embryol 49: 569-572, 2008.

29. Constantinescu AF, Ionescu M, Iovanescu VF, Ciurea ME, Ionescu AG, Streba CT, Bunescu MG, Rogoveanu I and Vere CC: A computer-aided diagnostic system for intestinal polyps identified by wireless capsule endoscopy. Rom J Morphol Embryol 57: 979-984, 2016.

30. Schaal C and Chellappan SP: Nicotine-mediated cell proliferation and tumor progression in smoking-related cancers. Mol Cancer Res 12: 14-23, 2014.

31. Paleari L, Catassi A, Ciarlo M, Cavalieri Z, Bruzzo C, Servent D, Cesario A, Chessa L, Cilli M, Piccardi F, et al: Role of alpha7-nicotinic acetylcholine receptor in human non-small cell lung cancer proliferation. Cell Prolif 41: 936-959, 2008.

32. Oh JJ, West AR, Fishbein MC and Slamon DJ: A candidate tumor suppressor gene, H37, from the human lung cancer tumor suppressor locus 3p21.3. Cancer Res 62: 3207-3213, 2002.

33. Bechara E, Sebestyén E, Bernardis I, Eyras E and Valcárcel J: RBM5, 6, and 10 differentially regulate NUMB alternative splicing to control cancer cell proliferation. Mol Cell 52: 720-733, 2013.

34. Sutherland LC, Wang K and Robinson AG: RBM5 as a putative tumor suppressor gene for lung cancer. J Thorac Oncol 5: 294-298, 2010
35. Ahmad Z, Rahim S, Zubair M and Abdul-Ghafar J: Artificial intelligence (AI) in medicine, current applications and future role with special emphasis on its potential and promise in pathology: Present and future impact, obstacles including costs and acceptance among pathologists, practical and philosophical considerations. A comprehensive review. Diagn Pathol 16: 24 , 2021.

36. Streba CT, Ionescu M, Vere CC and Rogoveanu I: Artificial intelligence and automatic image interpretation in modern medicine. In: Translational Bioinformatics and Its Application. Translational Medicine Research. Wei DQ, Ma Y, Cho W, Xu Q and Zhou F (eds). Springer, Dordrecht, pp371-407, 2017.

37. Venkadesh KV, Setio AAA, Schreuder A, Scholten ET, Chung K, W Wille MM, Saghir Z, van Ginneken B, Prokop M and Jacobs C: Deep learning for malignancy risk estimation of pulmonary nodules detected at low-dose screening CT. Radiology 300: 438-447, 2021.

38. Joy Mathew C, David AM and Joy Mathew CM: Artificial intelligence and its future potential in lung cancer screening. EXCLI J 19: 1552-1562, 2020.

39. MercuT IM, Ilia LC, TĂnasie CA, Ionescu M, MercuT R, PÎrvĂnescu V and Ciurea ME: Analysis of tumour related data and clinical features of eyelid carcinomas. Curr Health Sci J 46: 222-229, 2020.

40. Wojno TH: The association between cigarette smoking and basal cell carcinoma of the eyelids in women. Ophthalmic Plast Reconstr Surg 15: 390-392, 1999. International (CC BY-NC-ND 4.0) License. 